expeditions. Sometimes the best we can do for imaginative investigators is to leave them alone so that one thing can lead to another. Making it possible for physician-scientists to examine the mysteries of human physiology and disease in their own style may lead them into blind alleys, but sometimes to breathtaking new vistas. I believe this is as true now as it was in 1956, and I thank Vince Dole and the JCI for reminding me.
Address correspondence to: Jules Hirsch, Laboratory of Human Behavior \& Metabolism, Rockefeller University, 1230 York Avenue, New York, New York 10021, USA. Phone: (212) 327-8426; Fax: (212) 3277150; E-mail: hirsch@mail.rockefeller.edu.

1. Fruton, J.S., and Simmonds, S. 1953. General Biochemistry. John Wiley \& Sons, Inc. New York, New York, USA/London, United Kingdom. 940 pp.

2. Fredrickson, D., and Gordon, R.S., Jr. 1958. Transport of fatty acids. Physiol. Rev. 38:585-630.
3. Dole, V.P. 1956. A relation between non-esterified fatty acids in plasma and the metabolism of glucose. J. Clin. Invest. 35:150-154.

4. Gordon, R.S., and Cherkes, A. 1956. Unesterified fatty acid in human blood plasma. J. Clin. Invest. 35:206-212.

5. Trout, D.L., Estes, E.H., Jr., and Friedberg, S.J. 1960. Titration of free fatty acids of plasma: a study of current methods and a new modification. J. Lipid Res. 1:199-202.

6. Banting, F.G., Best, C.H., Collip, J.B., Campbell, W.R., and Fletcher, A.A. 1922. Pancreatic extracts in the treatment of diabetes mellitus. Can. Med. Assoc. J. 12:141-146.

\title{
The birth of clinical body plethysmography: it was a good week
}

\author{
John B. West \\ Department of Medicine, University of California, San Diego, La Jolla, California, USA.
}

\begin{abstract}
Nearly fifty years ago, Arthur B. DuBois, Julius H. Comroe Jr., and their colleagues published two papers on the use of body plethysmography to measure lung volume and airway resistance. These two articles in the JCI are almost the most-cited doublet in the Journal's entire archive. Remarkably, the methods described then are still in use today in clinical pulmonary function laboratories. Though body plethysmography had been used before, there were serious technical problems; it was extraordinary that DuBois managed to solve most of these in one week. Times have changed and molecular medicine now dominates the JCI, but these articles remind us that biomedical research goes beyond the molecular.
\end{abstract}

Congratulations to the JCI on the occasion of its 80 th birthday. Happily the editors have used the occasion to highlight two papers by Arthur B. DuBois, Julius H. Comroe Jr., and their colleagues on the use of the body plethysmograph. Together, these two papers hold the record as the fourth most-cited articles $(3,109$ times as of this writing) in the entire archive of the JCI $(1,2)$. Therefore, congratulations are also in order for Arthur DuBois, who continues to be productive nearly 50 years after these publications appeared and who celebrated his own 80th birthday last year. Julius Comroe Jr. died in 1984.

These two classic articles describe how the body plethysmograph can be used for measuring thoracic gas volume on the one hand and lung airway resistance on the other. The word "plethysmograph" derives from the Greek plethusmos mean-

Conflict of interest: The author has declared that no conflict of interest exists.

Citation for this article: J. Clin. Invest. 114:1043-1045 (2004). doi:10.1172/JCI200422992. ing "increase" and graphe meaning "writing" and usually refers to a device for determining changes in the volume of an organ or limb. The body plethysmograph measures changes in volume of the whole body and is essentially a rigid box in which the patient sits while the small changes of pressure in the box can be measured as he or she makes respiratory maneuvers (Figures 1 and 2). The basic principle is Boyle's law, that is, that the pressure and volume of a gas are inversely related at constant temperature.

Briefly, to measure lung volume, the patient makes an inspiratory effort against a closed airway and the resulting slight increase in volume of the lung reduces the free volume of air in the box, thereby increasing its pressure. At the same time, the increase in volume of the lung results in a reduction of pressure in

\section{Figure 1}

Arthur DuBois with the body plethysmograph that was used for the two classic papers discussed here. Reproduced with permission from the Journal of Applied Physiology (7). the airway; from the changes in the two pressures and the volume of the box, the volume of the lung can be derived. The calculation is simplified by displaying the two pressures on the $x$ and $y$ axes of an oscilloscope. In the modern pulmonary function laboratory, this is a much easier way of measuring lung volume than gas dilution techniques using, for example, helium equilibration or nitrogen washout. A diagram of the apparatus is shown in Figure 3 (1).

In the first article, the authors showed that the plethysmographic technique gave values for lung volume that were essentially the same as those obtained by

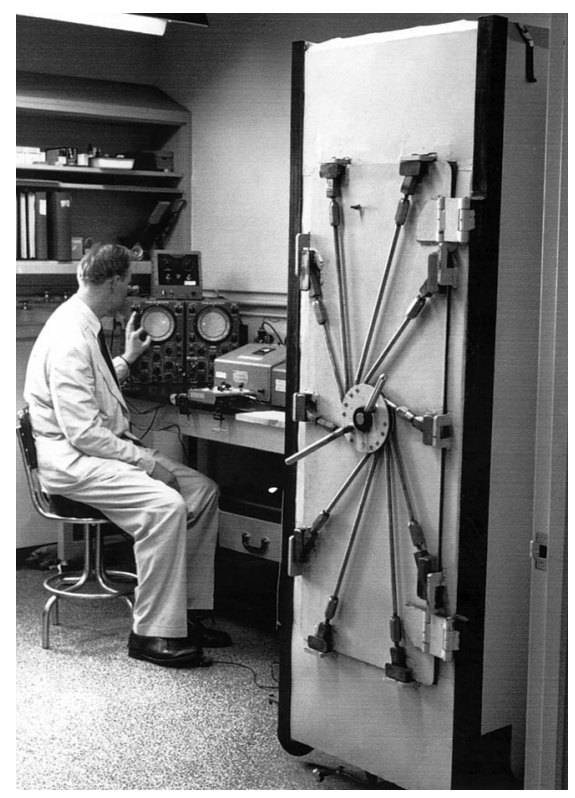




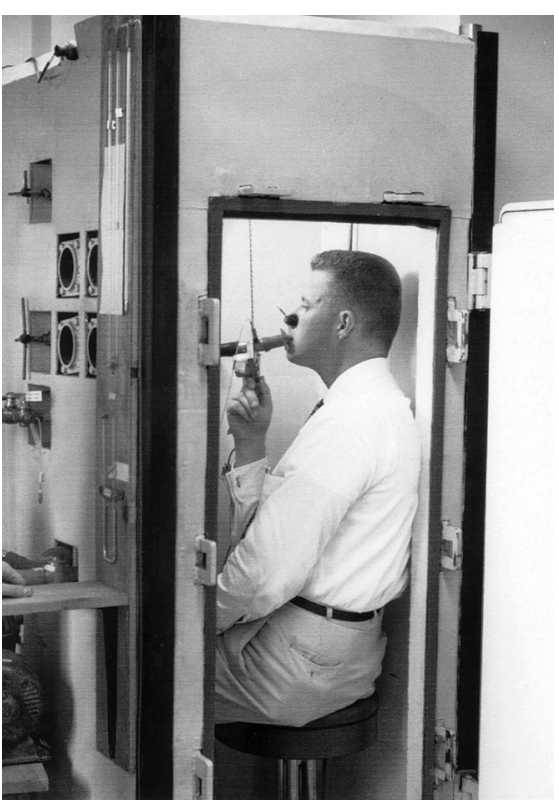

Figure 2

Body plethysmograph with the door open showing the subject seated and connected to the mouthpiece. Reproduced with permission from the Journal of Applied Physiology (7).

an open-circuit nitrogen washout technique. They also pointed out that the plethysmograph measurement includes gas in the abdominal cavity but that the amount is normally small enough (about $160 \mathrm{ml}$ ) for the resulting error to be ignored. They also noted that the plethysmograph method measures the total volume of compressible gas in the thorax, whether the gas is in communication with the airways or not. This is a valuable feature of the method in clinical practice because a comparison of the thoracic volume by this technique and by the helium dilution method measures the amount of non-ventilated or poorly-ventilated lung. This is useful information in some types of lung disease.

Airway resistance is measured in a somewhat similar way. The patient is asked to make rapid shallow breaths and, during inspiration, as the alveolar gas slightly expands, the box pressure rises slightly. This allows alveolar pressure to be calculated. The difference between alveolar and mouth pressure divided by flow rate is equal to airway resistance. A diagram of the apparatus is shown in Figure 4 (2).

The publication reported that the mean airway resistance of 21 normal subjects was $1.5 \mathrm{~cm} \mathrm{H}_{2} \mathrm{O}$ per liter per second at a flow rate of 1 liter per second panting, the standard deviation being \pm 0.49 . Measurements made on the same subjects on different days showed good reproducibility. Marked increases in airway resistance were seen in patients with airway obstruction in, for example, some cases of asthma, emphysema, and pneumoconiosis. One patient aged 51 with silicosis had an airway resistance of $10.8 \mathrm{~cm} \mathrm{H}_{2} \mathrm{O}$ per liter per second for a flow rate of 0.5 liters per second.

As with so many advances, there had been attempts to use body plethysmography before these classic studies. In fact, the eminent German physiologist Eduard Pflüger (1829-1910) described a "pneumonometer" as far back as 1882 (3). But there were many technical difficulties to be overcome. Jere Mead, in a historical account of pulmonary mechanics, pointed out that when a subject breathes inside a closed chamber, the pressure of the chamber is altered by three factors: the increase in temperature as a result of body heat, the change in the number of gas molecules as oxygen is taken up and carbon dioxide is eliminated, and any change in volume of some part of the gas (4). It is only the last effect that is of interest; the rest is noise. DuBois's contribution was to show that the signal-to-noise ratio could be vastly improved by the simple expedient of having the subject breathe shallowly and rapidly. That was the crucial step. DuBois's mentor, Comroe, was aware of the potential of body plethysmography for measuring airway resistance and lung gas volume and had the expensive equipment on hand when DuBois arrived (Figures 1 and 2). According to DuBois, when he moved in and quickly showed the way, "Julius was pleased it worked, but irritated that it only took a week."

For readers who would like to know more about the genesis of these two papers, we are fortunate to have a firsthand account by DuBois in the series "How it really happened," published in the American Journal of Respiratory and Critical Care Medicine (5). There he describes how the body box sat in a corner gathering dust because various investigators had not been able to overcome the technical problems but how in December 1953 the box was moved into a room and DuBois with it, in case he wanted to try his hand. Fortunately, he had the necessary background in fluid dynamics and mathematics together with the clinical skills needed to deal with patients with airway disease, and he describes the enormous "eureka" moment when he eventually got the pesky machine to work.

From a historical viewpoint, these articles are remarkable for several reasons. First, the methods described for measuring lung volume and airway resistance are still employed on an everyday basis in dozens of clinical pulmonary function laboratories throughout the world. How often can that be said of a methods paper published nearly 50 years ago?

A second interesting point is that it is very unlikely that the JCI would publish such articles today. For one thing, it is probable that not many present-day readers of the JCI would be interested in these papers or even be able to understand them. Such has been the burgeoning of molecular medicine over the last twenty years that areas such as physiology have

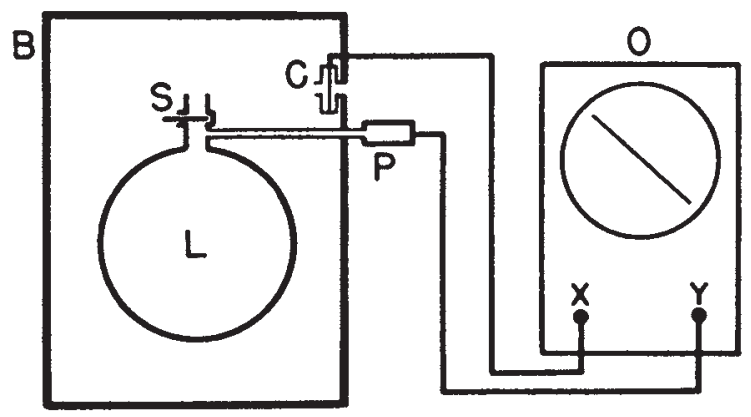

Figure 3

Diagram of the apparatus for measuring lung volume. B, body plethysmograph; S, shutter which occludes airway; L, lung; C, capacitance manometer to record pressure changes in the plethysmograph (which are proportional to the change in body volume); $\mathrm{P}$, capacitance manometer to record pressure changes in the mouth (which are equal to alveolar pressure when there is no airflow); $\mathrm{O}$, cathode ray oscillograph with $x$ and $y$ axes. Figure reprinted and legend adapted from ref. 1. 


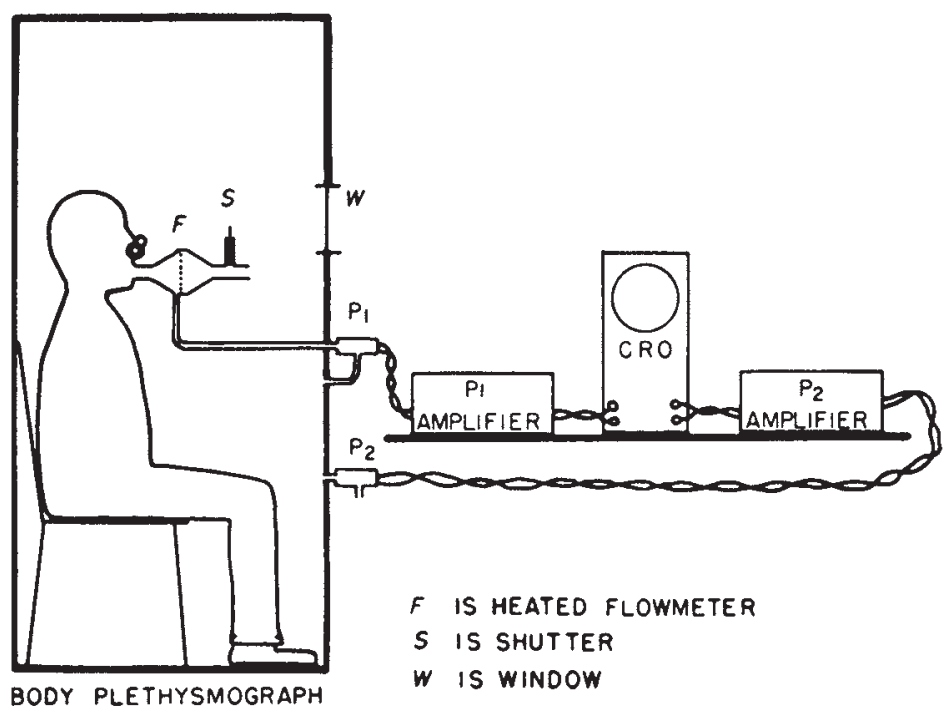

Figure 4

Diagram of apparatus for measuring airway resistance. Figure reprinted from ref. 2 .

been largely displaced. As an example, we have a strong Ph.D. program in biomedical sciences at UCSD which covers immunology, molecular biology, pharmacology, and physiology, but you would probably be hard put to find a graduate student who knew the meaning of adiabatic expansion of a gas, or the counterintuitive fact that the viscosity of a gas is independent of its pressure. A related trend is that our medical students taking their firstyear physiology course are sadly ignorant of elementary concepts in physics such as pressure, flow, resistance, inertia, and compliance. As in many other medical schools, our dean rules over an empire where the concrete never sets as more buildings devoted to molecular biology rise up like mushrooms. If you wanted to find students interested in the concepts described in these two classical papers, you would have to walk to the other side of the campus to the School of Engineer- ing where the Department of Bioengineering is very active but far removed from the Medical School.

Finally, it is remarkable that these articles were submitted to the JCI and accepted so quickly (the first article took only 28 days from submission to acceptance). The primary journals at the time for articles on lung mechanics were those of the American Physiological Society, notably the Journal of Applied Physiology, and most of the classic papers in that area can be found there. The field was dominated by people such as Fenn, Rahn, and Otis at the University of Rochester and Mead and Whittenberger at the Harvard School of Public Health. However, Comroe had a strong interest in what is currently called translational physiology, although that now-fashionable term would have been laughed at in the 1950s. Essentially every research project we embarked on then had its origins in some clinical or at least human problem. Comroe always had a great interest in the clinical potential of research and the first edition of his book The Lung (6) had an enormous impact and, incidentally, persuaded me to choose pulmonary medicine/physiology as a career.

In conclusion, it was a happy thought to include these two classical papers in the 80th birthday celebrations of the Journal. Those of us interested in respiratory physiology will get much pleasure from revisiting these classic studies that have influenced clinical pulmonary function testing to such an extent, and those readers with other interests will be reminded that biomedical research has many important areas beyond the molecular.

Address correspondence to: John B. West, UCSD Department of Medicine 0623A, 9500 Gilman Drive, La Jolla, California 920930623, USA. Phone: (858) 534-4192; Fax: (858) 534-4812; E-mail: jwest@ucsd.edu.

1. DuBois, A.B., Botelho, S.Y., Bedell, G.N., Marshall, R., and Comroe, J.H, Jr. 1956. A rapid plethysmographic method for measuring thoracic gas volume: a comparison with a nitrogen washout method for measuring functional residual capacity in normal subjects. J. Clin. Invest. 35:322-326.

2. DuBois, A.B., Botelho, S.Y., and Comroe, J.H., Jr. 1956. A new method for measuring airway resistance in man using a body plethysmograph; values in normal subjects and in patients with respiratory disease. J. Clin. Invest. 35:327-335.

3. Pflüger, E. 1882. Das pneumonometer. Pflügers Arch. Gesamte Physiol. Menschen Tiere. 29:244-246.

4. Mead, J. 1996. Mechanics of lung and chest wall. In Respiratory physiology: people and ideas. J.B. West, editor. Oxford University Press. New York, New York, USA. 173-207.

5. DuBois, A.B. 2000. Airway resistance. Am. J. Resp. Crit. Care Med. 162:345-346.

6. Comroe, J.H., et al. 1955. The lung: clinical physiology and pulmonary function tests (based on the 1954 Beaumont lecture). Year Book Medical Publishers. Chicago, Illinois, USA. 219 pp.

7. Comroe, J.H., Jr., Botelho, S.Y., and DuBois, A.B. 1959. Design of a body plethysmograph for studying cardiopulmonary physiology. J. Appl. Physiol. 14:439-444. 